\title{
Nova embalagem, mercadoria antiga
}

Élie Bajard

\section{Resumo}

Diante das intervenções institucionais dos promotores do método fônico na aprendizagem da escrita, visando substituí-lo ao caminho promovido pelos Parâmetros Curriculares, o artigo analisa dois textos representativos dessa nova frente: o Relatório entregue à Câmara dos Deputados do Brasil e um texto do Observatoire National de la Lecture (ONL), instituição referenciada no Relatório. Os dois textos analisados, expressando a visão do ONL, definem o ato de ler como uma seqüência de dois processos distintos: uma extração da pronúncia, seguida por uma extração da compreensão. Retomando a visão saussuriana que considera a língua escrita como uma mera representação da língua oral, o ONL vê nos grafemas apenas a tradução dos fonemas e, na leitura, a transposição dos primeiros nos segundos.

A especificidade da leitura, para os autores, encontra-se na 'decodificação'. Ao postergar a compreensão para uma segunda etapa, transformam a leitura em uma atividade que, operando fora do significado, deixa de ser um ato de linguagem.

A partir dessa visão da escrita, a proposta pedagógica promove conseqüentemente uma abordagem em duas etapas a serem seguidas pela totalidade das crianças, sem considerar a experiência personalizada anterior. No entanto, parcialmente letradas pelo contato com a literatura infanto-juvenil e pela escuta de textos de ficção, nem sempre as crianças começam pela extração da pronúncia, escapando assim ao programa previsto pelo $\mathrm{ONL}$.

Esse retorno de uma proposta que apresenta semelhanças com o método da cartilha, com sua seqüência decifração e leitura corrente, não pode constituir uma resposta às necessidades de um país que quer erradicar o analfabetismo funcional.

\section{Palavras-chave}

Didáticas - Alfabetização - Sistema gráfico - Sistema alfabético Compreensão.

\footnotetext{
Correspondência:

Élie Bajard

Rua Sergipe, 290 apto 162

01243-000 São Paulo
}

e-mail: emebaj@uol.com.br 


\section{New wrapping, old goods}

Élie Bajard

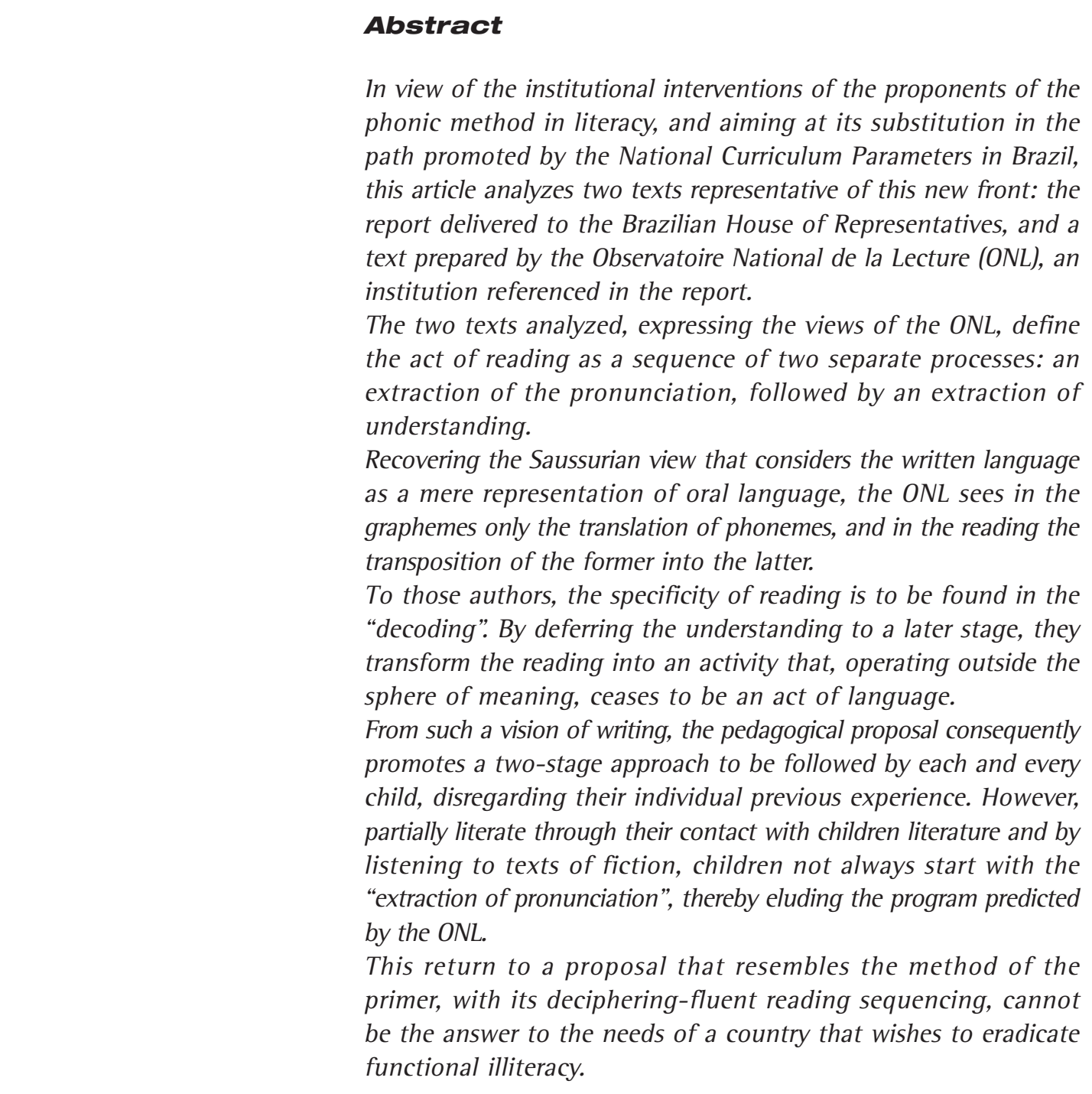

\section{Keywords}

Didactics - Literacy - Graphical system - Alphabetical system Understanding. 
Diante da persistência do analfabetismo funcional que os planos governamentais não conseguem reduzir de maneira significativa, observa-se atualmente o reaparecimento, nas políticas educacionais, de uma didática da escrita fundamentada na automatização da transposição das letras em sons. Essa abordagem vai de encontro às pesquisas e aos movimentos pedagógicos que possibilitaram a elaboração dos Parâmetros Curriculares Nacionais. Como já é sabido, os Parâmetros enfatizam a aprendizagem da língua escrita por meio do seu próprio uso, em uma alternância de "ação, reflexão, ação" (1997, p. 48) e definem a leitura como "um processo no qual o leitor realiza um trabalho ativo de construção do significado do texto" (1997, p. 53).

Uma tal didática, que promove uma decodificação prévia a qualquer construção de sentido, diz se basear na ciência atual. No Brasil, nomeada 'método fônico', ela se expressa, entre outras publicações, por meio de um Relatório entregue à Câmara dos Deputados (Brasil, 2003). Elaborado por uma equipe internacional coordenada por José Morais, o Relatório final do grupo de trabalho Alfabetização Infantil: os novos caminhos (Brasil 2003, p. 16) se refere explicitamente aos trabalhos do Observatoire National de la Lecture - ONL -, órgão influente do Ministério da Educação Nacional da França, entre os quais se destaca o texto La lecture et son apprentissage. Observatoire National de la Lecture. L'évolution de l'enseignement de la lecture en France, depuis dix ans (Fayol; Morais 2004).

São esses dois textos - o Relatório brasileiro e o texto francês do ONL - que pretendemos questionar neste artigo. Inicialmente criticaremos a apropriação exclusiva 'da ciência' pelo Relatório, que nega cunho científico a outras linhas de pesquisa sobre a alfabetização. Na seqüência, pretendemos mostrar o caráter redutor da aprendizagem da escrita exposta em ambos os textos, nos planos lingüístico, semiótico, psicológico e pedagógico.

\section{Argumentação polêmica}

Apesar de José Morais participar da redação de ambos os documentos, o estilo do texto francês é diferente do relatório brasileiro; não está recheado com expressões tais como: "todos esses estudos adotam procedimentos científicos bem estabelecidos e reconhecidos pela comunidade internacional" (Brasil, 2003 p. 17); "o estudo [o de Morais] rompeu com o mundo da especulação e do amadorismo” (Brasil, 2003 p. 17), presentes no Relatório apresentado na Câmara, além de outras similares, que parecem ter sido escolhidas com o objetivo de gerar confrontos e semear polêmicas. Graças a esses novos estudos, a pedagogia passaria a obedecer a regras científicas e se libertaria de seus antigos pontos de vista: "uma postura eminentemente política ou ideológica levou, em diversos países, e continua levando, no Brasil a uma rejeição de evidências objetivas e científicas sobre como as crianças aprendem a ler" (Brasil, 2003, p. 17). Esse novo pensamento 'científico' permitiria, então, salvar o Brasil da postura 'ideológica’: "as pesquisas atuais sobre a leitura obedecem às mesmas regras aplicáveis às demais ciências experimentais, como a física ou a biologia" (Brasil, 2003, p. 17). Mais adiante lemos:

A Sociedade Americana de Psicologia (ASP) publicou em sua revista Observer (volume 15 de julho-agosto de 2002) um relatório intitulado "How psychological science informs us about the teaching of reading”. Esse relatório ressalta que na nova Ciência Cognitiva da Leitura, o princípio de que a consciência fonológica é o mais importante preditor de sucesso em leitura possui a força equivalente à do conceito de gravitação em física. (p. 19)

Para os autores, as ciências humanas seriam epistemologicamente equivalentes às ciências do mundo físico! Paradoxalmente, o discurso emitido hoje pelos cientistas da natureza é menos messiânico que o mantido pelo Relatório.

A necessidade de recorrer compulsivamente ao argumento de autoridade da ciência acaba funcionando como denegação, gerando suspeitas sobre a força da própria argumentação. 0 Relatório, que recorre até à caricatura 
para desconsiderar o pensamento alheio, assemelha-se mais a um panfleto do que a um texto científico. 0 julgamento emitido por Fijalkow no que diz respeito a um outro livro publicado pelo ONL (1998) permanece pertinente em relação aos textos aqui examinados: "[trata-se de] um contexto onde se enfrentam inovadores de um lado, e, de outro, pesquisadores de laboratório separados da prática e políticos. Nesse aspecto, é o fruto da aliança dos dois últimos contra os primeiros" (Fijalkow, 1999, p. 51). Talvez a primeira atitude científica a ser adotada diante do Relatório deva ser de prudência e reserva diante de um estudo pretensamente tão promissor. Se o ONL evita recorrer a uma ciência salvadora, no entanto, os dois textos são ramificações irrigadas pela mesma veia.

Analisaremos a seguir a abordagem da aprendizagem da escrita exposta em ambos os textos. Como nossa análise operará a partir de vários pontos de vista, exemplificaremos cada um por um foco definido.

Pretendemos mostrar que:

- a lógica da argumentação deixa a desejar;

- a lingüística de referência, historicamente marcada, é redutora;

- a dimensão semiótica é esquecida, embora se trate de uma linguagem visual;

- a psicologia do ato de ler e da aprendizagem remete a uma concepção mecanicista e autoritária.

\section{Dupla extração}

0 texto começa por uma definição que já mostra a que veio: "Ler é extrair de uma representação gráfica da linguagem a pronúncia e o significado que lhe correspondem" (Fayol; Morais, 2004).

Se ler é definido como "extrair o significado', porque é preciso mencionar 'extrair a pronúncia'? Se o objetivo de extrair o significado for atingido, por que inserir na definição a maneira de fazê-lo? Definir a leitura por uma dupla extração exclui do ato de ler várias ati- vidades humanas que visam 'tomar conhecimento' - conforme uma das definições do item 'leitura' presente no dicionário (Houaiss, 2001, p. 1739) - sem extração de pronúncia. Assim, são excluídas do ato de ler, antes de qualquer debate ou investigação, várias práticas culturais que, no entanto, deveriam ser consideradas leituras. Vejamos algumas delas.

0 surdo que não se comunica pela língua portuguesa oral, mas somente pela língua dos sinais e extrai o significado do português escrito sem extrair a pronúncia, não estaria efetuando uma leitura? 0 acesso desse surdo à escrita não teria nada a ver com a leitura da pessoa ouvinte?

Além disso, como chamar a atividade do estudioso que pesquisa dentro de uma bibliografia estrangeira sem dominar a língua oral correspondente? Com efeito, a prática das línguas estrangeiras mostra que a aquisição de uma segunda ou terceira língua é freqüentemente parcial e nem sempre seu domínio é igual em todos os seus usos. Fatos como entender um discurso oral sem saber falar, ler sem saber falar etc. são comuns. Caso aceitássemos a argumentação do ONL, estaríamos supondo que um estudioso brasileiro que não fala inglês só poderia ter acesso ao sentido de um texto em língua inglesa se o pronunciasse com os fonemas da língua portuguesa, os únicos que conhece.

Como denominar o ato de 'tomar conhecimento' de um texto em ideogramas por um chinês? Quando se fundamenta a leitura na extração da pronúncia, o que se faz é isolar o ato de ler em língua portuguesa do ato de ler efetuado em outras línguas como, por exemplo, em escrita ideográfica tal como a chinesa, na escrita consonântica das línguas semíticas (árabe e hebraico) que não registram as vogais, sempre inferidas a partir da estrutura consonântica ou mesmo em determinadas escritas alfabéticas pouco 'transparentes', tal como o inglês.

Em todos esses casos, não existe extração de pronúncia anterior à extração do sentido. Ao contrário, a extração da pronúncia de um texto árabe, por exemplo, exige o reconhe- 
cimento prévio da palavra por meio da sua classe gramatical ${ }^{1}$ já que o substantivo e o verbo podem se apresentar com a mesma raiz consonântica. Nesse caso, é a extração do sentido que possibilita a extração da pronúncia. Será que o leitor de uma língua semítica, que inverte o processo, não está lendo? A visão dos autores tem um caráter eurocêntrico, uma vez que consideram o alfabeto, desde a invenção grega, como modelo acabado da escrita. Eles esquecem de considerar que as línguas latinas se afastaram do modelo alfabético grego quando o espacejamento foi introduzido na escrita.

É relevante analisar uma anedota histórica que, apesar de não aparecer no texto francês, é narrada pelo texto brasileiro:

\section{Depois que o poeta inglês Milton se tornou cego e resolveu reler os clássicos, ele ensinou suas filhas a decodificar textos em Grego, em- bora elas não pudessem compreender uma só palavra desse idioma. Podemos afirmar que Milton estava lendo? Não, ele simplesmente ouvia a leitura feita por suas filhas. Mesmo se fosse analfabeto, mas soubesse o Grego, ele poderia compreender. E as filhas de Milton, es- tariam lendo? Naturalmente que sim, elas esta- vam simplesmente lendo. (Brasil, 2003, p. 20)}

Certamente o poeta Milton, que apenas escutava - tal como a criança analfabeta escuta a proferição de um texto - não extraía o sentido do texto gráfico ${ }^{2}$, mas sim da escuta. Suas filhas pronunciavam-no, como debutantes em grego clássico são capazes de fazê-lo depois de três meses de exercício. As filhas do poeta realizavam a operação mecânica de uma vitrola que transforma a gravação de um disco em canção, mas não podiam compreender sua própria emissão sonora.

Aproveitando o que para nós é uma caricatura (o objetivo da alfabetização reduzido à ‘sonorização' das filhas de Milton), gostaríamos de fazer duas observações. A pronúncia das filhas de Milton não podia corresponder à língua grega. Os grafemas, com certeza, não eram convertidos em fonemas gregos, que talvez o próprio Milton desconhecesse, mas sim em fonemas ingleses. Outro ponto: o grego escrito submetido ao exercício das filhas de Milton, formatado de maneira moderna com espacejamento, não correspondia a um texto em scriptio continua da época helenística, que recorria a palavras emendadas sem espacejamento. Um tal formato teria dificultado, senão impossibilitado, a 'extração' da pronúncia. Fazemos essas observações para salientar que tanto as operações cognitivas realizadas por Milton, quanto aquelas efetuadas por suas filhas escapavam de uma prática real da língua grega.

Curiosamente, nesse exemplo presente no Relatório, o autor abandona a definição do ato de ler como extração dupla da pronúncia e do sentido, reduzindo-o apenas à da pronúncia. Caso tivesse mantido a postura da dupla extração, a leitura resultaria do trabalho conjunto das filhas e do pai: as primeiras pronunciando e o outro entendendo.

\section{Ler e entender}

Para os autores em questão, "a dimensão de compreensão, apesar de ser imprescindível e crítica, não é específica à leitura, já que se exercita na visão de um filme, numa conversa e na escuta de uma palestra" (Fayol; Morais, 2004). Nessa citação, a distinção entre ler e entender é feita com pertinência, pois muitas vezes a leitura é definida apenas como ato de compreensão. Em sala de aula, são nomeadas 'leitura' múltiplas operações de compreensão. A escuta do texto proferido, por exemplo, é chamada leitura com os ouvidos. Nessa ótica, todas as crianças saberiam ler antes de serem alfabetizadas! Como todas as atividades de comunicação são impregnadas de compreensão, definir a leitura apenas pela presença de operações de compreensão é, efetivamente, insuficiente.

1. Encontramos em português um fenômeno análogo no par pronúncia/ pronuncia.

2. Distinguimos o texto gráfico, apreendido pelos olhos, do texto sonoro, apreendido pelos ouvidos. Os dois são representações do texto escrito armazenado na memória do computador. 
No entanto, a partir dessa observação, os autores elaboram uma argumentação equivocada. Segundo eles, já que o ato de compreensão pertence a todas as atividades de comunicação, não é nele que se situa a especificidade da leitura, mas sim na decodificação, "competência central do processo de aprendizagem da leitura” (Brasil, 2003 p. 36). Para aceitar tal raciocínio, seria necessário mostrar que o ato de compreensão é idêntico em todas as suas manifestações. Nesse caso, não poderia então servir para definir nenhuma delas. Façamos uma analogia com a navegação. A propulsão, elemento comum à navegação à vela e à navegação a vapor, não poderia, segundo esse raciocínio, servir para a definição nem de uma nem de outra modalidade.

De fato, tanto a escuta de uma conversa quanto a leitura de um texto requerem compreensão. No entanto, a distinção entre ambas pode originar-se no tipo de compreensão exercitado e não em um processo externo a ela. Assim, a argumentação utilizada assemelha-se, ao nosso ver, a um sofisma.

Segundo os autores, a extração da pronúncia (leitura) transforma a escrita em discurso oral. Este, por ser escutado, acaba sendo compreendido. Assim os textos instalam uma dicotomia entre dois procedimentos, a extração da pronúncia e a extração da compreensão, que não se justifica. Para nós, ler consiste em 'extrair o sentido' (para utilizar a terminologia pouco satisfatória dos autores) e para fazê-lo existem vários procedimentos historicamente atestados, inclusive o da extração da pronúncia.

\section{Nível lingüístico}

Os defensores do método fônico consideram a língua escrita como uma representação da língua oral: "os sistemas alfabéticos representam a fala” (Brasil, 2003, p. 10). 0 princípio é questionável não por ser errado, mas por ser insuficiente. Algumas reflexões históricas podem ajudar a esclarecer tal insuficiência.

0 alfabeto nasceu da transposição dos fonemas em letras por meio de várias metamorfo- ses. Os gregos, assumindo radicalmente o aspecto fonético da escrita (século IX a.C.) suprimiram o espaço entre as palavras, presente na escrita fenícia, uma vez que o espaço não correspondia a nenhum som, fazendo prevalecer uma escrita perfeitamente alfabética, a scriptio continua, com correspondências biunívocas entre grafemas e fonemas (Saenger, 1998). Na ldade Média, a partir do século IX, foi reintroduzido o espacejamento entre as palavras e, mais tarde, a minúscula e a pontuação. Uma dimensão ideográfica foi desse modo incorporada à lógica puramente alfabética, dado que o acesso ao texto, que até então ocorria por meio de sua oralização, passou a ser também visual, ou seja, silencioso, sem depender da pronúncia. Essas mudanças contribuíram para a autonomia da escrita - hoje reconhecida - em relação à língua oral (Ong, 1998).

Apesar das inúmeras pesquisas contemporâneas (Olson, 1997; Goody, 1986) que destacam essa autonomia, o fonocentrismo permanece preso a uma concepção de escrita que corresponde a uma outra época. Inscreve-se na lingüística de Saussure, para quem "a única razão da existência [da escrita] é representar [a fala]" (Saussure, 1969, p. 34). Essa lingüística foi fundada com a ambição de libertar a análise da língua de suas raízes escritas, tendo em vista expandir seu campo às línguas sem escrita. Assim sendo, a fonologia inventou um método endógeno para identificar suas unidades - os fonemas - sem compará-las a unidades escritas. Dessa maneira, elaborou um instrumento apto à descrição de todas as línguas, escritas ou não.

Como a língua oral funciona sem estar necessariamente ligada a um sistema escrito, o fonema é definido sem referência à língua escrita, como a menor unidade sonora capaz de produzir uma diferença de sentido. Por que então, na língua escrita, ficar atrelado à definição exógena do grafema - Nina Catach (1996) - segundo a qual essa unidade é constituída pelas letras correspondentes a um fonema? Se hoje a escrita funciona com uma relativa autonomia, por que definir a unidade escrita apenas a partir da sua relação com a língua oral? Se- 
guindo o modelo da definição endógena do fonema, estamos propondo uma definição também endógena do grafema: a menor unidade gráfica capaz de produzir uma diferença de sentido. A partir dessa análise, as unidades a serem identificadas seriam outras, isto é, aproximadamente as do teclado do computador. A esse respeito, é importante destacar que o teclado não foi construído a partir da fonologia, mas sim a partir de uma lógica tátil e gráfica.

Alguns estudiosos, na herança de Hjelmslev, investigam esse ponto de vista:

Os lingüistas podem [...] considerar que a língua existe sob duas formas, entre as quais a lingüística não postula nem hierarquia nem dependência. É neste plano [...] que construímos um modelo autonomista que implica uma descrição imanente da língua escrita. (Anis, 1996, p. 213)

\section{Observemos que:}

- no teclado do computador, o acento ocupa uma tecla igual à das letras, enquanto a maior tecla marca um grafe sem valor sonoro: o espaço; - a oposição maiúscula/minúscula não tem correspondência sonora, mas produz uma diferença de sentido entre o nome próprio Rosa e o substantivo comum rosa.

Escrever uma palavra com o computador supõe manipular essas unidades gráficas. A relação da letra com o fonema passa assim para um segundo plano. Numa época em que as crianças usam o teclado antes do lápis e os adolescentes manipulam com habilidade o celular, no qual a mesma tecla comanda três ou quatro letras, é necessário estar atento ao funcionamento do sistema gráfico sem ficar preso exclusivamente a sua dimensão alfabética. Nessa perspectiva, todos os grafes (letra, minúscula, acento, pontuação, espacejamento) se tornam unidades de uma segunda articulação no nível visual.

A aprendizagem da leitura preconizada pelo ONL se vale da ciência lingüística e reivindica sua introdução na pedagogia. No entanto, essa novidade data dos anos de 1970 e a teoria lingüística utilizada, que provém dos anos de 1950, está ainda presa a uma visão fonocêntrica (Derrida, 1999).

\section{Nível semiótico}

Essa abordagem endógena, ainda pouco investigada, traz conseqüências para o funcionamento semiótico do texto. Sendo um sistema endereçado à vista, a escrita possui, antes de mais nada, um valor icônico. lsso quer dizer que qualquer grafe compõe uma imagem com seus vizinhos. Essa função ideográfica, universal, aproxima a escrita portuguesa não só das outras escritas alfabéticas, mas também das escritas consonânticas ou mesmo ideográficas (Sampson, 1996). 0 conjunto dos grafes compõe o sistema gráfico que opera semioticamente por meio de uma dimensão ideográfica. Nessa abordagem, o sistema alfabético com suas relações fonográficas se torna um subconjunto do sistema gráfico. Todos os grafes possuem valor ideográfico, enquanto apenas uma parte deles possui valor sonoro.

Se considerarmos o sistema ortográfico de maneira larga, verificaremos que ele acaba se superpondo ao sistema gráfico. Na perspectiva tradicional, ocorre o oposto. A ortografia se constitui de exceções no que diz respeito às relações entre 'sons e letras'. É uma 'sobra', uma excrescência do sistema alfabético: o texto fala de "ortografia inconsistente" (Fayol, Morais, 2004). Por isso, "a primeira dificuldade - a descoberta do principio alfabético e das correspondências fonográficas - deve ser, pelo menos, parcialmente resolvida antes que a segunda - a aprendizagem do sistema ortográfico - seja abordada" (Fayol; Morais, 2004).

Assumindo uma visão mais complexa da língua escrita, podemos considerar dois níveis de funcionamento:

1) No nível interno, isto é gráfico, o conjunto das unidades, 'os grafes', possibilita escrever qualquer texto; cada palavra possui uma configuração visual proveniente do conjunto e da 
ordem das letras utilizadas, assim como de seus limites marcados por um espaço branco (Alain disse que se reconhece a palavra como se reconhece o navio, pela silhueta das suas velas, seu 'gréement'3). A palavra helicóptero, por exemplo, composta de letras com hastes ascendentes e descendentes, outras sem hastes constrói uma imagem singular. Esse caráter visual da grafia, atestado por numerosos estudiosos (Sampson, 1996), chamado ideográfico (ou logográfico quando opera no nível da palavra), parece negado pelos autores do Relatório.

2) Na sua relação com a língua oral, as letras remetem a fonemas, constituindo assim o sistema alfabético, o único relevante para os autores em questão.

Para distinguir os dois modos de identificação, podemos tomar como exemplo duas grafias de um mesmo nome: G. W. Bush e Jedabliubâch, que evidenciam o duplo modo de acesso ao nome do presidente dos USA ${ }^{4}$. Na segunda grafia, domina a dimensão alfabética, enquanto na primeira, a ideográfica tem primazia.

A semiótica visual está ausente nos dois textos aqui abordados. Podemos dizer brincando que, se no mundo dos surdos a passagem pelas sonoridades é impossível, no mundo do "Observatoire" a configuração visual está tão fora do universo dos autores, quanto da percepção do poeta cego Milton.

Se o reconhecimento de logomarcas como Coca-Cola, McDonald ou do próprio nome pelas crianças pequenas não é mencionado no texto do Observatoire, no Relatório é considerado como um "processamento rudimentar" (Brasil, 2003, p. 33) a ser abandonado. Na medida em que a dimensão logográfica da leitura é ignorada, os autores acabam desvalorizando o 'processamento' infantil em lugar de considerá-lo como a primeira manifestação de um processo ideográfico, âncora possível para uma aprendizagem da via direta.

A leitura fluente do leitor experiente é atribuída não a um procedimento logográfico específico, mas à aceleração da extração da pronúncia: "implica que o reconhecimento e a identificação sejam automáticos” (Brasil, 2003, p. 6). Assim o acesso direto "ao léxico mental ortográfico" (Fayol; Morais, 2004) efetuado pelo leitor experiente, seria oriundo, segundo os autores, de uma aceleração da ‘decodificação' - uma automatização - e não de uma operação outra, ideográfica, isto é, baseada numa percepção imagética. Segundo essa ótica, o ato de ler do chinês não encontraria nenhuma semelhança com a leitura do homem ocidental.

Curiosamente, a recusa da dimensão ideográfica, como modo de apreensão visual da palavra em favor da dimensão exclusivamente fonográfica, acaba levando a um paradoxo. Se a extração da pronúncia é o procedimento primeiro que, de acordo com os autores, se exerce sobre a palavra, devemos reconhecer que essa unidade gráfica é apreendida visualmente, antes de qualquer ‘decodificação', por meio do espacejamento, isto é, a partir de um grafe - o espaço branco - sem correspondência sonora. Assim, a logografia, nem sequer mencionada pelos autores, dá suporte, à revelia deles, a um método que a rejeita.

$\mathrm{Na}$ transposição da língua escrita em língua oral preconizada pelos autores, apenas os elementos isomorfos - 'em correspondência' nos dois sistemas são considerados. Enquanto a língua escrita é constituída de grafemas organizados em palavras e a língua oral é formada de fonemas organizados por uma prosódia dentro da qual eles se apresentam fundidos, os autores consideram apenas os componentes (grafemas e fonemas) que constituem a interseção entre ambas as manifestações da língua. As particularidades de cada uma das representações da língua - prosódia de um lado e palavras separadas do outro - são abandonadas. Trata-se assim de uma dupla redução.

Para os autores, a língua escrita deve ser transposta em matéria sonora para ganhar existência. Restrita às suas características grafofonéticas,

3. Metáfora atribuída ao filósofo francês Alain (1868-1951), citada com freqüência. Encontra-se, entre outros, em Fijalkow. Disponível em: <http:/ /www. bienlire.education.fr/01-actualite/document/fijalkow.pdf $>$. Acessado em: 31 janeiro 2006.

4. A grafia 'USA' é, inclusive, muitas vezes pronunciada 'Estados Unidos' pelo brasileiro, que não soletra a sigla. 
o sistema gráfico acaba se reduzindo ao sistema alfabético. Réplica da oralidade, a língua escrita não seria suscetível de ser submetida a uma semiótica, reduzindo-se assim à sua função de memória da oralidade. Não seria uma linguagem em si mesma; não teria capacidade de construir diretamente o pensamento.

Segundo os autores, o grafema remete individualmente ao fonema. Sua relação visual com os outros fonemas, isto é, a figura que compõe com os vizinhos, é de certa forma negada. A configuração visual da palavra inexiste. As experimentações perceptivas feitas por Javal, no século XIX, não são consideradas.

É necessário mencionar que no item 'Ler e compreender' (Fayol, Morais, 2004), os autores integram aos problemas de compreensão vários aspectos das ciências contemporâneas da linguagem, tais como o tratamento da inferência e da anáfora, descrito pela análise do discurso. No entanto, para eles, esses componentes operam posteriormente ao reconhecimento das palavras e à sua decodificação; a escrita não se configura como representação da língua, mas somente como réplica da oralidade, a única suscetível de proporcionar acesso ao significado.

Esse afastamento do sentido se verifica também por meio do peso atribuído à 'pseudopalavra' como indicador de leitura, uma vez que se trata de unidade sem significado. Como a pseudopalavra é uma unidade constituída apenas por elementos alfabéticos, a extração da sua pronúncia não corre riscos de ser contaminada por outros procedimentos (inferência, imagem etc.). Uma vez que exclui qualquer interferência contextual na sua decodificação, a pseudopalavra suscitaria uma leitura 'pura'. Por isso, passa a ser um indicador central da avaliação da leitura do método fônico. A pseudopalavra, signo com significado perdido, torna-se emblema de uma escrita desgarrada da linguagem.

\section{Nível psicológico}

$\mathrm{Na}$ visão foneticista da leitura, o esquema simbólico da decodificação é simples e linear. As letras da palavra 'faca', por exemplo, remetem ao significante sonoro /faka/, o qual ativa a palavra armazenada na memória (Figura 1). Trata-se de operações que transformam grafemas em fonemas, possibilitando a identificação da palavra. Dão assim acesso ao signo lingüístico - e ao seu significado - dominado na língua oral. Esse processo "lento [que] opera da esquerda à direita e mobiliza recursos atencionais” (Fayol; Morais, 2004) é, nós concordamos, exigente em energia cognitiva.

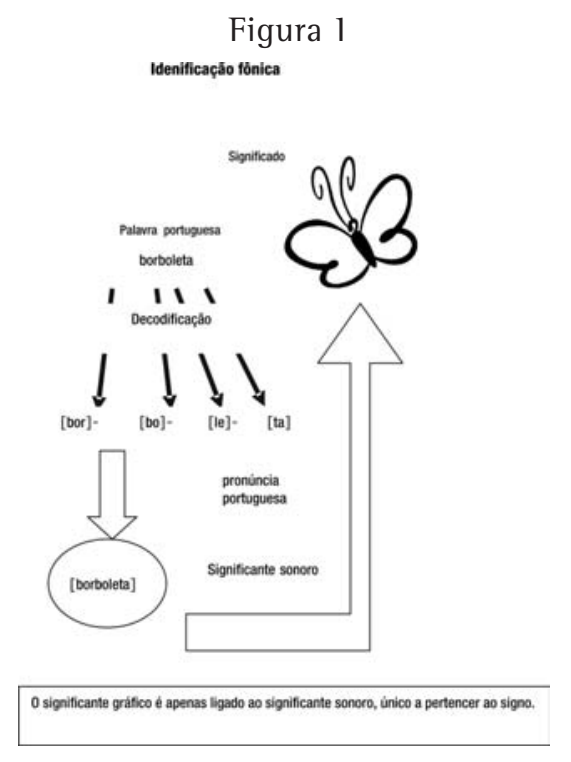

No entanto, para os autores, o aperfeiçoamento da decodificação acontece com a sua aceleração, gerando automatismo: o tratamento das palavras conhecidas deve tornar-se o mais rápido e automático possíve ${ }^{5}$ (Brasil, 2003, p. 15). Assim, dentro da abordagem fônica, existe um único processo de ativação do léxico armazenado na memória - a decodificação - desenvolvido pelo leitor iniciante com lentidão e pelo leitor experiente com velocidade.

Para Giasson (2000, p. 62), ao contrário, existem dois processos de ativação da palavra armazenada na memória. Um primeiro - que pode recorrer (ou não) à decodificação -, nomeado

5. No entanto, se um automatismo como a troca de marchas de um carro é executado sem reflexão, a seqüência dos gestos que o compõem, apesar de ser ultra-rápida, nunca se realiza em um tempo igual a um desses gestos. Na leitura, ao contrário, uma palavra de cinco letras é apreendida com a mesma velocidade que uma letra isolada. 
identificação, cria o vínculo entre o significante visual e o conceito já dominado na língua oral. Um segundo, chamado reconhecimento, recorre ao vínculo já criado pela identificação. Esse segundo processo, ideográfico, incide sobre um significante visual e é distinto do primeiro.

Por isso, a ativação da palavra realizada unicamente por seu significante oral deve ser questionada. Essa representação é suficiente para explicar a decodificação, mas não vale para o ato de ler. 0 acesso direto ao léxico - por 'endereçamento' 6 - precisa de outro modelo de referência para escapar de uma explicação mecanicista como a da aceleração da decodificação.

Recusamos que a razão de ser da grafia se deva apenas à sua relação com fonemas; preferimos conceber o signo como um nó de vínculos complexos ${ }^{7}$. 0 conjunto visual de grafes, limitado por espaços, constituindo a imagem da palavra, sua ortografia, vem, no decorrer da aprendizagem, integrar-se a esse nó, assim como outros significantes, tais como o gesto da língua dos sinais no caso dos surdos, a pronúncia da palavra em língua estrangeira etc. Essa imagem se incorpora ao signo sonoro já armazenado na memória e o torna mais complexo. Assim sendo, qualquer constituinte desse nó - e no nosso caso, a imagem gráfica - pode ativar o signo completo, inclusive nos seus componentes sonoros (Figura 11).

É a integração da imagem gráfica ao conjunto do signo que possibilita o 'endereçamento', também nomeado acesso direto. Como atinge diretamente o conceito na sua complexidade, o acesso direto implica uma operação de linguagem, com sua dimensão semântica, e não somente uma transposição de grafemas em fonemas.

A concepção estritamente fônica da escrita ignora o reconhecimento imediato, instantâneo, 'global', da semiótica visual de Bertin (1977), da teoria da Gestalt ou dos estudiosos da dimensão ideográfica da escrita. Exclui a possibilidade de integração da imagem do conjunto de grafemas ao nó já constituído pela língua oral. Nessa visão, o grafema vinculado individualmente ao significante sonoro não forma, com os outros grafemas da palavra, uma configuração visual capaz de ativar diretamente o conceito armazenado, mas deve transitar pelo significante sonoro.

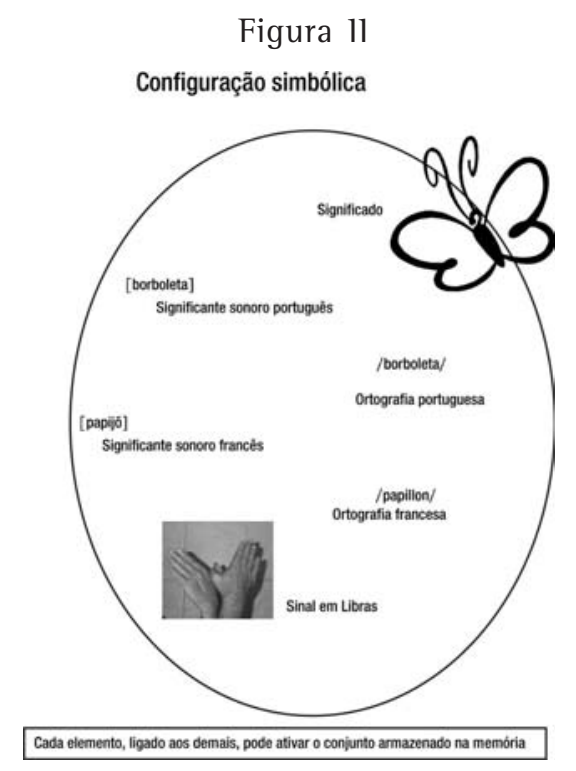

Para nós, a leitura se vale de dois processos. 0 primeiro, esporádico, recorre à decodificação para elucidar o material desconhecido. 0 outro, contínuo, trata ideograficamente o material conhecido. 0 leitor experiente utiliza de maneira pontual a decodificação - que para ele também permanece lenta - e de maneira corrente a leitura ideográfica - rápida, por ser visual. 0 acesso direto ao léxico não remete à aceleração de um processo a decodificação -, mas à sua substituição por um outro - o ato ideográfico.

Ao longo dos dois textos analisados, manifesta-se um pressuposto não explicitado: o processo psicológico de utilização de uma linguagem seria apenas determinado pela lógica da sua descrição. Isto é, se a lingüística descreve a escrita a partir da língua oral, o ato de ler acaba se submetendo a essa descrição. Como diz Foucambert, isso equivale a se perguntar: "Dado que a água é composta de oxigênio e hidrogênio,

6. Adressage em francês.

7. Estes podem corresponder no cérebro a um nó de conexões neurais (Pinker, 2002). 
como Lucien aprende a nadar?" (Foucambert; Chenauf, 1997). Uma outra metáfora na própria área da visão pode nos aproximar de nosso tema. Apesar do fato de uma imagem colorida ser composta de três cores primárias (azul, amarelo, vermelho-magenta), a interpretação de uma ilustração colorida não requer a identificação dessas três cores primárias. 0 fato de a escrita ser constituida de unidades gráficas em relação biunívoca com os fonemas, não acarreta obrigatoriamente que 0 ato de ler implique passar pelos fonemas para tratar os grafemas. Da mesma maneira, a formatação digital da escrita pelo computador, baseada em elementos binários (0 e 1) não exige dos usuários o domínio dessa codificação para que possam escrever. 0 isomorfismo entre a descrição lingüística da escrita e o procedimento psicológico do ato de ler é apenas uma hipótese de trabalho e exige comprovação. De toda maneira, é preciso distinguir a análise de um fenômeno de sua utilização na prática educativa.

Ao reduzir a língua escrita aos elementos em correspondência com a língua oral, os autores sugerem que a transposição dos grafemas em fonemas por si só possibilita inferir a complexidade da língua oral. No entanto, como traduzir grafemas em prosódia? Como se pode verificar, as crianças emitem, freqüentemente, seqüências de fonemas sem conseguir constituir um texto sonoro.

\section{Nível da aprendizagem}

Como consideram a extração da pronúncia separadamente da extração do sentido, os autores do ONL propõem um caminho que rompe com a aprendizagem de outras linguagens, tais como a da língua oral materna e a de línguas estrangeiras. Contudo, sabemos que nas aprendizagens linguageiras é por meio de situações de comunicação que o código é descoberto e dominado. Trata-se não de dominar um código para atingir a mensagem, mas de conquistar um código mediante a prática linguageira.

A metodologia fônica parte dos elementos simples rumo aos elementos complexos, como se o simples fosse também fácil. As etapas vão dos grafemas até o sentido, passando sucessivamente por sua transposição em fonemas, pela identificação da palavra, pelo domínio da frase e do texto. Nessa necessidade de extrair a 'pronúncia' antes 'do sentido', de 'decodificar' a palavra antes de compreendê-la, de dominar o sistema alfabético antes de atingir a compreensão, sempre a abordagem do sentido é relegada a uma fase posterior. 0 método adia o acesso à compreensão, obrigando a criança a cumprir tarefas mecânicas para atingila. Não é à toa que a criança dedicada apenas à decodificação - isto é, a uma atividade que opera fora de qualquer significado - apresenta dificuldades para elaborar o sentido, como o atesta a massa de analfabetos funcionais.

A dicotomia entre decodificação e compreensão não se sustenta. Como aceitar que uma atividade humana não seja informada pelo sentido? A própria escolha do texto não seria incentivada pelo conteúdo que o leitor espera descobrir? A identificação da palavra seria realizada na ignorância do sentido trazido pelo contexto da frase, do texto ou da imagem? A apreensão da palavra poderia realizar-se fora das expectativas do leitor? Como afirmar que existem operações iniciais (decodificação) anteriores à influência do significado, desprovidas de qualquer sentido?

\section{Nível pedagógico}

Ao propor a abordagem da leitura pela extração da pronúncia, o $0 \mathrm{NL}$ está centrado no método. A aprendizagem, inteiramente prevista pela instituição acadêmica, determina o caminho da criança. Desde a educação infantil, a estrutura fonética da língua oral começa a ser ensinada, sob a justificativa de que a consciência fônica é correlata às competências de leitura. Se os autores do texto francês evitam fazer da consciência fonológica uma causa que determina inteiramente a aprendizagem da leitura - "as relações entre consciência fonológica e aprendizagem da leitura são recíprocas" (Fayol, Morais, 2004) -, essa mesma consciência fonológica chega a se substituir ao objetivo de leitura, na medida em que 
a extração da pronúncia é vista como anterior à extração do sentido.

Paradoxalmente, esse desprezo da compreensão dentro do processo da alfabetização ocorre em um momento em que o mundo da infância se apodera da literatura. Uma literatura infanto-juvenil de qualidade está florescendo tanto no Brasil como na Europa. Sustentada pelas demandas da classe média, ela invade não apenas os lares, mas as bibliotecas públicas e escolares e outras salas de leitura. Hoje no Brasil, a venda de livros endereçados às crianças ultrapassa a dos livros para adultos. Algumas 0NGs como, por exemplo, $A$ cor $d a$ letra, formam jovens mediadores de leitura para atuar em hospitais, creches, orfanatos ou em praças e jardins públicos. A expansão dos acervos de livros contradiz a concepção dicotômica do ONL, constituída de uma fase de aprendizagem e uma outra de utilização. De fato, o encontro com o livro antecede a aprendizagem e, ao mesmo tempo, a proporciona. Essa nova prática social e escolar leva inevitavelmente a questionar as metodologias da alfabetização.

Esse encontro precoce com os acervos inaugura a entrada das crianças na literatura, iniciação esta que se efetua em duas frentes. Diretamente, isto é, sem intervenção de um mediador, a criança manuseia o livro, brinca com ele, encena seus personagens em dobradura, interpreta a seqüência de suas imagens, observa a presença do texto, descobre elementos do código gráfico que não se reduzem ao código alfabético tais como a maiúscula, o travessão etc. Ao mesmo tempo, a criança que se beneficia da intervenção vocal de um mediador escuta textos e assim, mesmo sem ser alfabetizada, penetra no mundo da ficção escrita. Várias aprendizagens são construídas por meio do contato precoce com o livro:

- descoberta, por meio de brincadeiras infantis, do livro como objeto sensível;

- descoberta do livro como portador de histórias;

- descoberta das três matérias da narrativa: icônica, sonora e gráfica;
- identificação dos personagens;

- interpretação narrativa das imagens;

- escuta do texto como ritual de entrada na literatura;

- aproximação da especificidade do texto como elemento distinto da imagem;

- descoberta da sua permanência, oposta à flexibilidade do discurso oral;

- descoberta da necessidade de aprendizagem para poder ler;

- constituição de um 'banco' de palavras escritas no qual o próprio nome da criança é gerador;

- levantamento gradativo do material gráfico (diversidade das letras, maiúscula/minúscula, acentos, pontuação, espacejamento);

- levantamento gradativo das relações grafofonéticas.

0 alfabetizador não pode ignorar o percurso letrado anterior à escolarização. 0 professor de primeira série não pode mais ser o anfitrião da iniciação à escrita, que ocorre muito antes da alfabetização formal: a escolha da metodologia deve levar esse fato em consideração.

Ao contrário desse processo, a metodologia do ONL prevê fases sucessivas nas quais a descoberta do princípio alfabético deve anteceder a aprendizagem do sistema ortográfico. Essa proposta, que não é suscetível de ser modificada, nem pela ordem das descobertas das crianças nem pelas mutações sociais em curso em nosso mundo, retoma, mutatis mutandis, o programa da cartilha.

Uma vez que "a descoberta do princípio alfabético deve ser no mínimo parcialmente resolvida" (Fayol, Morais, 2004) antes da abordagem do sistema ortográfico, os elementos do código ideográfico não são considerados, apesar de já serem suscetíveis de identificação pela criança pequena. Com um programa assim cristalizado em fases, os autores não podem integrar no seu modelo as descobertas infantis, como propõe Bajard (2002). Por que adiar a abordagem do código gráfico (maiúscula) e começar autoritariamente pelo código alfabético sem considerar a cultura diversificada já adquirida pela criança no seu contato com o livro? 
0 texto do Observatoire pretende impor um procedimento seqüencial, fundado na primazia da extração da pronúncia, transgredido pelas crianças familiarizadas com o contato do livro. A observação sistemática das sessões de mediação mostra que as habilidades construídas pelas crianças mediante a prática do livro não seguem a ordem prevista. 0 código alfabético nem sempre é descoberto em primeiro lugar; o papel da maiúscula ou do travessão é às vezes percebido antes do valor sonoro das letras. A abordagem da escrita pela palavra é também suscetível de transgressão: grafes da frase ou do texto podem ser identificados antes dela, como o ponto de interrogação, por exemplo.

0 método apresentado não considera a cultura da escrita da criança nem seus modos de apropriação. A proposta até poderia contemplar uma criança padrão, sem desejos, sem história, sem vinculação com um meio social determinado, enfim, uma criança de laboratório. Tal abordagem valoriza mais o ensino do professor do que a aprendizagem da criança real, que cotidianamente convive com a escrita "de fato, ao contrário da aquisição da identificação das palavras faladas ${ }^{8}$, a identificação das palavras escritas não se faz espontaneamente pela exposição à escrita" (Fayol; Morais, 2004).

Já que o significado é excluído do início do processo em benefício do ato mecânico da decodificação, o sentido acaba sendo igualmente excluído do texto gráfico (qual é o interesse desse texto para mim?), do ato de ler (ler para quê?) e enfim da aprendizagem (aprender para quê?). Os autores do ONL pretendem adiar a extração do sentido para depois da extração da pronúncia, mas como fazê-lo quando a criança atribui sentido ao livro antes de entrar na escola?

\section{Mercadoria antiga}

Os autores instauram uma distinção entre a decodificação, específica ao ato de ler, e a compreensão, comum a todas as atividades humanas. Essa dicotomia aparece desde a definição do ato de ler concebido com uma dupla operação, em seqüência, de extração da pronúncia e extração do significado. Tecem uma teoria em duas etapas, sem levar em consideração a dimensão ideográfica da escrita e sem combiná-la à dimensão alfabética. Recorrem a argumentos científicos parciais para justificar uma abordagem da escrita que não deixa de ser um eco da metodologia da escola tradicional. A antiga seqüência decifração - leitura corrente cede lugar a uma nova formulação: extração da pronúncia - extração do sentido.

Como no método tradicional, a extração da pronúncia opera não apenas fora da ortografia, mas também fora da gramática, que nunca é convocada para a identificação da palavra. No entanto, as unidades homófonas /a/ e /à/, por exemplo, precisam ser identificadas como palavras diferentes. Dentro de uma abordagem investigativa, a observação da crase pode ocorrer antes do previsto pelo método tradicional. Quando crianças observam, por exemplo, que na frase Você vai à festa aparece um tracinho sobre o /a/ (situação problema), o professor pode conduzir um questionamento de modo a que encontrem uma solução provisória para esse problema. Mais tarde, a criança poderá deduzir, por exemplo, que a palavra precedida por /à/ nunca exige acordo com o verbo; em outras palavras, nunca é sujeito.

Essa teoria do ONL em duas fases explica qualquer dificuldade de leitura pela escassez do domínio da 'decodificação'. 0 acesso à compreensão se encontra assim sempre adiado pelo domínio insuficiente da extração da pronúncia. Vale a pena ler com atenção o texto de Gombert mencionado por Morais:

Todos os professores já encontraram alunos que são capazes de decodificar textos sem compreendêlos... Por isso muitos professores desconfiam do ensino da decodificação... A solução [no entanto] não consiste em abolir o ensino da decodificação, mas, ao contrário, ensinar o aluno a ler automati-

8. A aquisição da identificação das palavras faladas se faria, para os autores, pela simples exposição? 
camente através do exercício repetido desse tipo de atividade. (Brasil, p. 38)

É um exemplo de "uma receita que ao fazer mais da mesma coisa é uma 'solução' que cria o problema” (Watzlawick; Weekland, 1977) e alimenta a queixa compulsiva do professor: "eles lêem mas não entendem". Se é necessário adiar o ensino da compreensão até o domínio da decodificação, como estranhar que muitos alunos, apesar de alfabetizados, contribuam ainda para o aumento das coortes do analfabetismo funcional?

A metodologia apontada representa um passo atrás em relação aos pressupostos do construtivismo. Conforme os métodos ativos, Emília Ferreiro (1987) explica que o domínio da linguagem se constrói por meio da sua prática, que as crianças aprendem integrando, a um sistema provisório já estruturado, novos elementos por elas descobertos. Assim, as descobertas não se realizam necessariamente na ordem prevista pelo método nem tampouco na mesma ordem para todas as crianças.

É necessário salientar que a metodologia do Observatoire - e a fortiori a do Relató- rio - não corresponde aos desafios do mundo contemporâneo. Uma vez que, hoje, a criança se inicia na literatura antes da idade da escolarização formal, o programa estabelecido pelo método do ONL se torna caduco. 0 professor não pode mais reivindicar para si o monopólio da responsabilidade do início do letramento, já que a criança o experimenta bem antes de seu ingresso na primeira série. É desde o primeiro encontro com o livro que ela tenta dar significado a esse objeto. A atividade de compreensão pode iniciar-se desde os primeiros anos de vida; a criança não vai esperar o domínio do alfabeto para iniciar suas operações de busca do sentido.

0 método fônico, avatar do método tradicional, não pode ajudar a sociedade a reduzir o analfabetismo funcional por ela produzido em massa. Os jovens e adultos assim 'alfabetizados' conhecem o código alfabético, transformam letras em sons ou, para falar como os autores do $\mathrm{ONL}$, praticam a correspondência entre grafemas e fonemas. No entanto, permanecem analfabetos funcionais, uma vez que não sabem utilizar a escrita como uma forma de linguagem distinta da oralidade, imprescindível ao homem contemporâneo.

\section{Referências bibliográficas}

ANIS, J. Uma grafemática autônoma. In: CATACH, N. Para uma teoria da língua escrita. São Paulo: Ática, 1996, p. 213-224.

BAJARD, É. Caminhos da escrita: espaços de aprendizagem. São Paulo: Cortez, 2002. 303 p.

BERTIN, J. Sémiologie graphique: la graphique et le traitement graphique de l'information. Paris: Flammarion, 1977. 267 p.

BRASIL. Relatório final do grupo de trabalho "Alfabetização infantil: os novos caminhos". Apresentado no seminário "0 poder legislativo e a alfabetização infantil: os novos caminhos". Câmara dos Deputados, Comissão de Educação e Cultura. Brasília, 15 de setembro de 2003

CATACH, N. Para uma teoria da língua escrita. São Paulo: Ática, 1996. 261 p.

DERRIDA, J. Gramatologia. São Paulo: Perspectiva, 1999. 386 p.

FAYOL, M.; MORAIS, J. La lecture et son apprentissage. Observatoire National de la Lecture. L'évolution de l'enseignement de la lecture en France, depuis dix ans In: Journées de l'ONL. Clermont-Ferrand. Disponível em: <http://www.inrp.fr/ONL/ressources/ publi/publications_tot.htm>. Acesso em: janeiro de 2004.

FERREIRO, E.; GOMEZ-PALACIO, M. Os processos de leitura e escrita. Porto Alegre: Artes Médicas, 1987. 273 p. 
FIJALKOW, J. Un coup pour rien. Les Actes de Lecture. n. 67. Septembre, 1999.

FOUCAMBERT, J.; CHENOUF, Y. Usages expert de l'écrit. Projet de recherche INRP, Département Didactique des Disciplines, Unité Didactique des Apprentissages de Base. Disponível em: <http://www.inrp.fr/> . Acesso em: avril/septembre 1997.

GIASSON, J. A compreensão na leitura. Lisboa: ASA, 2000. 320 p.

GOODY, J. Lógica da escrita e organização da sociedade. Lisboa: Edições'70, 1986.

HOUAISS, A. Dicionário da língua portuguesa. Rio de Janeiro: Objetiva, 2001.

OLSON, D. 0 mundo no papel: as implicações conceituais e cognitivo da leitura e da escrita. São Paulo: Ática, 1997. 340 p.

ONG, W. Oralidade e cultura escrita. São Paulo: Papirus, 1998. 224 p.

ONL Apprendre à lire au cycle des apprentissages fondamentaux (GS,CP,CE1): analyses, réflexions et propositions. Paris: Odile Jacob, 1998.

Parâmetros Curriculares Nacionais: Língua Portuguesa. Brasília, Ministério da Educação e do Desporto, 1997, p. 48.

SAMPSON, G. Sistemas de escrita: tipologia, história e psicologia. São Paulo: Ática, 1996.

SAUSSURE, F. Curso de lingüística geral. São Paulo: Cultrix, 1969. 280 p.

SAENGER, P. A leitura nos séculos finais da Idade Média. In: CAVALLO, G.; CHARTIER, R. História da leitura no mundo ocidental. São Paulo: Ática, 1998, p.147-149.

WATZLAWICK, P. F.; WEAKLAND, J. Mudança: princípios de formação e resolução de problemas. São Paulo: Cultrix, 1977.

Recebido em 21.10.05

Modificado em 13.06.06

Aprovado em 26.06.06

Élie Bajard é doutor em Lingüística pela École des Hautes Études em Sciences Sociales (Paris). Ex-professor de l'Institut de Formation des Maîtres de Reims (França), ex-adido Lingüístico no Brasil, criador do Projeto Nacional Pró-Leitura (19881994), ex-professor convidado da ECA/USP (1999-2004). Assessor em várias ONGs, tal como no projeto Aprender para ensinar do Museu de Arte Moderna de São Paulo, endereçado a jovens surdos, alunos da Divisão de educação e reabilitação dos distúrbios da comunicação, da PUC de São Paulo, tendo em vista serem monitores do museu (2005 até hoje). 